\title{
Phytoprotection
}

\section{Mot du comité du centenaire}

\section{Gilles Émond et Léon-M. Tartier}

Volume 89, numéro 2-3, décembre 2008

Journée commémorative du centenaire de la société de protection des plantes du Québec

Centennial Commemoration of the Québec Society for the Protection of Plants

URI : https://id.erudit.org/iderudit/038231ar

DOI : https://doi.org/10.7202/038231ar

Aller au sommaire du numéro

Éditeur(s)

Société de protection des plantes du Québec (SPPQ)

ISSN

0031-9511 (imprimé)

1710-1603 (numérique)

Découvrir la revue

Citer cet article

Émond, G. \& Tartier, L.-M. (2008). Mot du comité du centenaire. Phytoprotection, 89(2-3), 49-49. https://doi.org/10.7202/038231ar d'utilisation que vous pouvez consulter en ligne.

https://apropos.erudit.org/fr/usagers/politique-dutilisation/ 


\section{Mot du comité du centenaire}

Un centenaire, ça se fête en grand! C'est pourquoi le comité du centenaire a choisi le lieu grandiose qu'est le Musée national des beaux-arts du Québec pour commémorer cette journée. Dès sa fondation en 1908 au Collège Macdonald de I'Université McGill, la Société de protection des plantes du Québec (SPPQ) regroupait des personnes se préoccupant déjà des pertes annuelles occasionnées par les insectes, les maladies et les mauvaises herbes dans les champs cultivés au Québec. Déjà à cette époque on s'inquiétait des répercussions que pourraient avoir les systèmes modernes de transport rapide sur l'entrée au pays de ravageurs en provenance de l'extérieur.

Aujourd'hui, nos préoccupations demeurent sensiblement les mêmes. Cependant, les moyens de lutte et les programmes de dépistage et de prévention permettent une répression plus efficace des ravageurs dans un contexte de développement agricole et forestier durable.

Cette journée commémorative se veut avant tout une journée de rassemblement et de retrouvailles où les membres, les anciens membres et les amis de la SPPQ se rappelleront les meilleurs moments de leur carrière à travers les exposés des conférenciers, le contenu des affiches regroupées dans les kiosques et, évidemment, lors d'échanges au moment du dîner, du cocktail et du banquet du centenaire.
Comme il se doit, le banquet sera servi par le Restaurant du Musée, reconnu pour sa gastronomie. Trois événements majeurs suivront ces agapes : la remise de la Bourse étudiante du centenaire SPPQ 2008 Margaret-Newton; la présentation des prix et hommages décernés à des pionniers de la SPPQ, à des services publics et à des leaders qui ont contribué à l'avancement de la protection des plantes au Québec et qui ont joué un rôle important dans le rayonnement de la Société; et enfin, le dévoilement d'une plaque commémorative pour souligner le $100^{\mathrm{e}}$ anniversaire de la SPPO.

Le centenaire de notre Société mérite d'être souligné de façon magistrale, compte tenu que cette dernière est la plus ancienne société scientifique au monde consacrée à tous les champs et disciplines reliés à la protection des plantes.

Gilles Émond, président du comité du centenaire Léon-M. Tartier, secrétaire

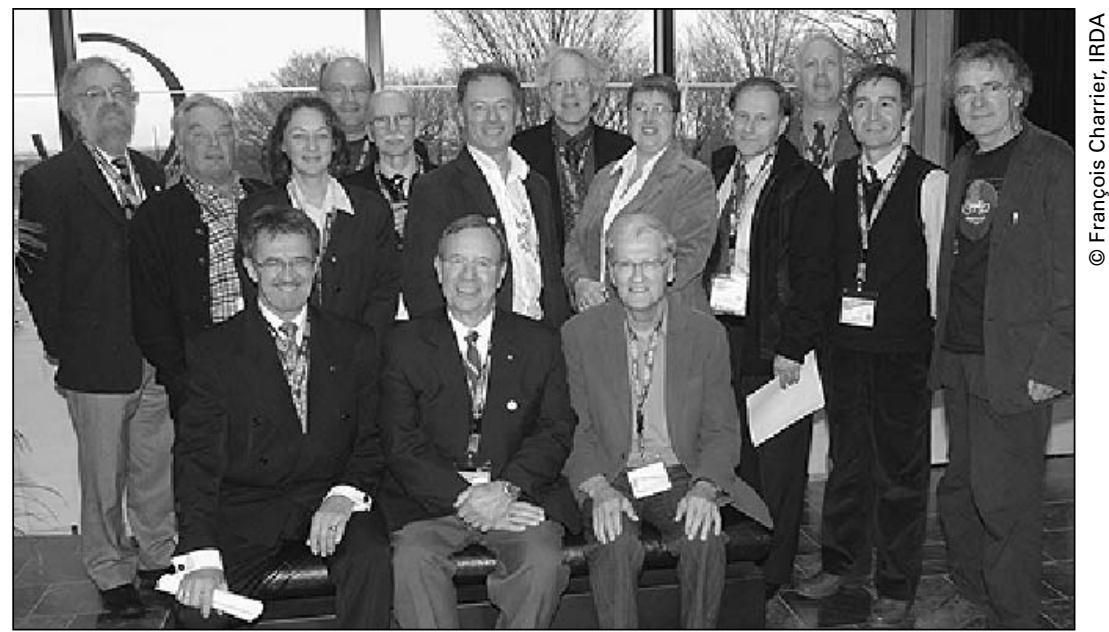

Membres du comité. Assis: Gilbert Banville, Gilles Émond et Guillemond Ouellette. Debout: Gaston Laflamme, Léon-M. Tartier, Sylvie Rioux, Danny Rioux, Claude Richard, Guy Bélair, Daniel Dostaler, Danielle Bernier, Luc Couture, Richard Hogue, Gérard Gilbert et Conrad Cloutier. Anne Légère et Valérie Gravel sont absentes sur la photo. 